\title{
A new vision for sexual and reproductive healthcare in the UK
}

\author{
Chris Wilkinson, ${ }^{1}$ Jane Hatfield ${ }^{2}$
}

\begin{abstract}
${ }^{1}$ President, Faculty of Sexual \& Reproductive Healthcare, London, UK

${ }^{2}$ Chief Executive, Faculty of Sexual \& Reproductive Healthcare, London, UK
\end{abstract}

\section{Correspondence to} Dr Chris Wilkinson, Faculty of Sexual \& Reproductive Healthcare, 27 Sussex Place, Regent's Park, London NW1 4RG, UK; president@fsrh.org

Received 15 November 2015 Accepted 15 November 2015

\section{CrossMark}

To cite: Wilkinson $C$,

Hatfield J. J Fam Plann Reprod

Health Care 2016:42:3-4.

\section{BACKGROUND}

November 2015 saw the launch of the UK Faculty of Sexual \& Reproductive Healthcare's (FSRH's) vision for sexual and reproductive healthcare (SRH). ${ }^{1}$ This was the culmination of a process that began in 2011, when the FSRH's President, Chris Wilkinson, initiated a process of change. Recognising that the FSRH, as the UK's largest professional membership organisation working in sexual health, needed an overhaul of its governance, structure and function, he commissioned former President, Alison Bigrigg, to review how the Faculty was working and to set out where it should aim to be by 2020 . Based on interviews with a wide range of people closely involved in the FSRH and the Royal College of Obstetricians and Gynaecologists (RCOG), Bigrigg set out key ambitions for the coming 10 years. ${ }^{2}$ With 5 years to go until 2020, it seems timely to consider what progress has been made and what challenges remain.

\section{PAST PROGRESS AND FUTURE CHALLENGES}

Established in 1993, the founders of what was then called the Faculty of Family Planning, foresaw that 'family planning' was evolving into a more holistic and recognised area of healthcare and that 'SRH', as it later become known, needed its own criteria, skills and requirements for continuing education and further recognition. Predominantly established as an educational body, the FSRH has been at the forefront of the development of training, qualifications, standards and clinical guidance in UK SRH, as well as running events for its members and producing a quarterly academic journal.

Bigrigg's report ${ }^{2}$ recognised what a turning point the establishment of the new medical specialty of community SRH (cSRH) in 2010 had been for sexual healthcare delivery in the UK. She saw the FSRH's potential both to widen its membership and play a greater leadership role in promoting the specialty and enhancing the status, education and training of all those working within it. She defined key areas for modernisation needed to meet these challenges, including developing the FSRH's governance and management systems and addressing the needs of the increasingly divergent four countries of the UK. Bigrigg's report armed the FSRH with the vision it needed to shape progress over the coming decade. So what progress has been made?

20:20 Vision ${ }^{2}$ initiated changes aimed at making the organisation more proactive and externally focused. For example, the new staffing structure now includes two policy roles aimed at influencing national health and social care at a time of particular change across the four nations of the UK. Membership of the Academy of Medical Royal Colleges is enabling the Faculty to develop alliances across other areas of healthcare, as the recent unanimous Academy response to the cuts to funding of public health services demonstrated. And investment in new technology will enable the Faculty to provide more efficient and cost-effective services to its $15500+$ members, keeping subscription rates low, compared with those of other institutions. In addition, two elected FSRH Officers who are general practitioners have broadened representation of the membership at leadership level.

\section{LAUNCH OF FSRH 'VISION'}

The November 2015 launch of the new 'vision' 1 was accompanied by a new brand and identity for the organisation. These two entities are related. Wide consultation with FSRH members generated repeated calls for a strong organisation to champion SRH and women's health at a time when this is under political and 
budgetary threat. Members urged us not to be afraid to speak out on behalf of the membership, arguing that as a key representative of SRH, the FSRH needs to be more visible to those who influence and shape health policy and practice. Members also said that we should continue to promote the importance of SRH in the wider medical field as well as championing the needs of women and men using our services. We hope that our new 'identity' will help to increase the visibility of SRH and - more importantly - help to highlight why people need effective, community-based integrated SRH that treats them with respect based on recognised high standards.

We will be following up the 'vision', which sets out the principles on which all SRH should be based, by developing implementation plans for each of the four countries. These will be written in collaboration with our 'country' committees in Wales, Scotland, Northern Ireland and England; each plan will identify actions needed to achieve good care in each country.

We know that this is not about the FSRH working alone to achieve higher standards in SRH and we are looking forward to building on our existing partnerships - with the RCOG, Royal College of General Practitioners, Royal College of Nursing, specialist societies, voluntary organisations and commissioners and others - to help to achieve this improvement in care.

\section{MEMBERSHIP AND EDUCATION}

Membership and education remain our raison détre and we want to ensure that our qualifications and training continue to be both relevant and accessible. We opened up Diplomate membership to nurses over 18 months ago as the first of what we believe will be many steps towards a well-supported career and training path for nurses working in SRH. We are now actively exploring whether other healthcare professionals could become FSRH members by assessment and look forward to welcoming our first Affiliate members (a membership category open to anyone with an interest in SRH) in January 2016. Also ensuring a better service to our members, the coming year will see the introduction of the Faculty's new website, which will be accessible, easy to navigate and will enable those pursuing membership and/or qualifications to do so online. We are not yet the 'paper-less' or 'cheque-less' office that we aspire to be but we are definitely on the way. We are proud that we have succeeded in investing in staff and new technology without increasing membership fees significantly, and in investing more of our income in influencing policymakers and decision makers as well as in making improvements to the accessibility of our qualifications.

\section{THE FUTURE}

So what next for the FSRH? As a relatively small organisation providing core educational functions, and with ambitions to influence health and social care policy, we need to build alliances. From Officers and Council to the wider membership, we will continue to nurture a wealth of relationships, connections and partnerships. This is crucial. Practitioners working in sexual health have always understood that people's bodies - and their health/reproductive needs - do not fit into separate medical specialties and we have always understood this concept. To serve our members well we need to continue to develop links with others and to bring a better understanding of SRH to other medical specialties, as well as to those commissioning and delivering social care. In other words, we need to look outwards. Not so that we grow for the sake of it, but so that we can have more impact, at a time when sexual health care is under threat. It is ironic that just when the Faculty is getting stronger, funding for SRH is more vulnerable. Strong leadership in SRH has never been more important, and the FSRH is increasingly in a position to take a leadership role. Part of that leadership is to encourage and support others in championing SRH. We look forward to working with our existing and new members, and with other organisations, to achieve better sexual health outcomes for all.

\section{Competing interests None declared.}

Provenance and peer review Commissioned; internally peer reviewed.

\section{REFERENCES}

1 Faculty of Sexual \& Reproductive Healthcare (FSRH). Better Care, a Better Future: A New Vision for Sexual and Reproductive Health Care in the UK. London, UK: FSRH, 2015.

2 Faculty of Sexual \& Reproductive Healthcare (FSRH). 20:20 Vision: FSRH Focussed Strategic Review for Implementation 2013-2015. London, UK: FSRH, 2013. 